\title{
Induction and decay of functional complement-fixing antibodies by the RTS,S malaria vaccine in children, and a negative impact of malaria exposure
}

Liriye Kurtovic ${ }^{1,2}$, Paul A. Agius ${ }^{1,3}$, Gaogian Feng ${ }^{1}$, Damien R. Drew¹, Itziar Ubillos ${ }^{4}$, Jahit Sacarlal ${ }^{5,6}$, John J. Aponte ${ }^{4,5}$, Freya J. I. Fowkes ${ }^{1,3,7}$, Carlota Dobaño ${ }^{4,5}$ and James G. Beeson ${ }^{1,2,8,9^{*}}$

\begin{abstract}
Background: Leading malaria vaccine, RTS,S, is based on the circumsporozoite protein (CSP) of sporozoites. RTS,S confers partial protection against malaria in children, but efficacy wanes relatively quickly after primary immunization. Vaccine efficacy has some association with anti-CSP IgG; however, it is unclear how these antibodies function, and how functional antibodies are induced and maintained over time. Recent studies identified antibodycomplement interactions as a potentially important immune mechanism against sporozoites. Here, we investigated whether RTS,S vaccine-induced antibodies could function by interacting with complement.
\end{abstract}

Methods: Serum samples were selected from children in a phase IIb trial of RTS,S/AS02 $2_{A}$ conducted at two study sites of high and low malaria transmission intensity in Manhiça, Mozambique. Samples following primary immunization and 5-year post-immunization follow-up time points were included. Vaccine-induced antibodies were characterized by isotype, subclass, and epitope specificity, and tested for the ability to fix and activate complement. We additionally developed statistical methods to model the decay and determinants of functional antibodies after vaccination.

Results: RTS,S vaccination induced anti-CSP antibodies that were mostly $\lg G 1$, with some $\lg G 3$, $\lg G 2$, and $\lg M$. Complement-fixing antibodies were effectively induced by vaccination, and targeted the central repeat and Cterminal regions of CSP. Higher levels of complement-fixing antibodies were associated with IgG that equally recognized both the central repeat and C-terminal regions of CSP. Older age and higher malaria exposure were significantly associated with a poorer induction of functional antibodies. There was a marked decay in functional complement-fixing antibodies within months after vaccination, as well as decays in lgG subclasses and IgM. Statistical modeling suggested the decay in complement-fixing antibodies was mostly attributed to the waning of anti-CSP IgG1, and to a lesser extent lgG3.

(Continued on next page)

\footnotetext{
* Correspondence: beeson@burnet.edu.au

${ }^{1}$ Burnet Institute, Melbourne, Australia

2Department of Immunology and Pathology, Monash University, Melbourne,

Australia

Full list of author information is available at the end of the article
}

(c) The Author(s). 2019 Open Access This article is distributed under the terms of the Creative Commons Attribution 4.0 International License (http://creativecommons.org/licenses/by/4.0/), which permits unrestricted use, distribution, and reproduction in any medium, provided you give appropriate credit to the original author(s) and the source, provide a link to the Creative Commons license, and indicate if changes were made. The Creative Commons Public Domain Dedication waiver (http://creativecommons.org/publicdomain/zero/1.0/) applies to the data made available in this article, unless otherwise stated. 


\begin{abstract}
(Continued from previous page)
Conclusions: We demonstrate for the first time that RTS,S can induce complement-fixing antibodies in young malaria-exposed children. The short-lived nature of functional responses mirrors the declining vaccine efficacy of RTS,S over time. The negative influence of age and malaria exposure on functional antibodies has implications for understanding vaccine efficacy in different settings. These findings provide insights into the mechanisms and longevity of vaccine-induced immunity that will help inform the future development of highly efficacious and longlasting malaria vaccines.
\end{abstract}

Keywords: Antibody function, Circumsporozoite protein, Complement, Malaria, Plasmodium falciparum, RTS,S, Vaccines,

\section{Background}

There is an unmet need for highly efficacious malaria vaccines, which would substantially reduce worldwide morbidity and mortality and accelerate malaria elimination. To date, only one candidate has been tested in phase III clinical trials, the RTS,S subunit vaccine administered with $\mathrm{ASO1}_{\mathrm{B}}$ adjuvant (liposome-based adjuvant). Thousands of children and infants were enrolled from multiple study sites across sub-Saharan Africa, and RTS,S was moderately efficacious against clinical malaria at $38-48$ months follow-up (36.3\% and $25.9 \%$ after the fourth booster at 20 months in children and infants, respectively) [1]. RTS,S has received a positive scientific opinion by the European Medicines Agency [2] and will undergo pilot implementation in areas of Ghana, Kenya, and Malawi to further evaluate vaccine safety, reduction in childhood mortality, and feasibility of the four-dose vaccine regimen $[3,4]$. Despite this achievement, vaccine efficacy against clinical malaria was well below the target of $75 \%$ as set by the World Health Organization [5], and longitudinal studies show that protection rapidly declines after vaccination [1].

RTS,S is based on the major surface expressed antigen on Plasmodium falciparum sporozoites, the circumsporozoite protein (CSP). The vaccine construct is a fusion protein between a truncated form of CSP (containing the central repeat and C-terminal regions only) and hepatitis B surface antigen that is co-expressed with unfused hepatitis B surface antigen, which self-assemble as virus-like particles. The central repeat region is a tandem repeat of amino acid sequence NANP that is a known $B$ cell epitope, and the $C$-terminal region contains $B$ and $T$ cell epitopes [6]. High levels of immunoglobulin G (IgG) to the central repeat region have been broadly associated with protection against clinical malaria in RTS,S vaccine trials [7]. A recent study was the first to report the specific IgG subclass responses induced by RTS,S/AS01 ${ }_{\mathrm{B}}$ in infants and young children (age groups, 6-12 weeks and 5-17 months) and identified that IgG3 to the central repeat region and IgG1 and IgG3 to the C-terminal region were associated with protection [8]. However, the mechanisms of such antibodies and how they confer protection are undefined. Further research is needed to understand the mechanisms of RTS,S-induced immunity and why efficacy is short-lived so that strategies to enhance vaccine efficacy and longevity in target populations can be developed.

Healthy malaria-naïve adults vaccinated with RTS,S develop antibodies that can block sporozoite infectivity and mediate opsonic phagocytosis using the THP-1 monocyte cell line in vitro. How this relates to protection is somewhat unclear, particularly for the latter mechanism, which has had conflicting findings [9-11]. Complement fixation and activation by antibodies is an important mechanism of humoral immunity to some viral and bacterial pathogens [12-14] and has been proposed to play a role in immunity against blood-stage $P$. falciparum infection [15]. We have recently demonstrated that naturally acquired human antibodies, or antibodies generated by repeated experimental inoculation of healthy volunteers with sporozoites, can promote fixation of complement factor $\mathrm{C} 1 \mathrm{q}$ and activate the classical complement pathway against $P$. falciparum sporozoites [16, 17]. This antibody-complement interaction inhibited the traversal mode of sporozoite motility and led to cell death. Antibodies targeting CSP could also promote complement fixation [17]. Additionally, high levels of naturally acquired complement-fixing antibodies were associated with a reduced risk of clinical malaria in a longitudinal study of children [17]. This indicated that antibody-complement activity is an important mechanism of human immunity against sporozoites and raised the question of whether it may also be a functional mechanism induced by RTS,S.

Here, we examined antibody responses from a phase IIb clinical trial of RTS,S administered with $\mathrm{ASO2}_{\mathrm{A}}$ adjuvant (formerly used adjuvant that is an oil-in-water emulsion) in children resident in Manhiça, Mozambique, that was conducted at two study sites of different malaria transmission intensity [18]. We aimed to characterize RTS,S-induced antibodies by isotype, IgG subclass, and reactivity to different CSP regions, and to determine whether antibodies induced by RTS,S function by fixing complement. Furthermore, we aimed to 
understand the influence of antibody types and levels of malaria exposure on complement-fixing activity. We then developed statistical models of the decay of complement-fixing antibodies, IgG subclass responses, and IgM over 5 years of follow-up and explored which responses influenced the decay of complement-fixing antibodies.

\section{Methods}

\section{Study participants}

Serum samples were obtained from a previously conducted randomized control phase IIb clinical trial of the RTS,S/AS02 ${ }_{\mathrm{A}}$ vaccine (ClinicalTrials.gov registry number NCT00197041). The study was conducted in Mozambique at two study sites to evaluate protective efficacy against clinical disease (Manhiça, cohort 1) and new infection (Ilha Josina, cohort 2). Notably, malaria transmission intensity was low to moderate at the Manhiça study site and high at the Ilha Josina study site. Children aged 1 to 4 years were enrolled and administered three doses of RTS,S/AS02 ${ }_{\mathrm{A}}$ at months 0,1 , and 2 of the study or comparator vaccines as previously described [18]. We tested sera from a random selection of participants collected at baseline (month 0, M0) and 30 days after receiving the third and final RTS,S vaccination (month 3, M3) from Manhiça (RTS,S $N=50$, comparator $N=25$ ) and Ilha Josina (RTS,S $N=49$, comparator $N=$ 24) cohorts. We additionally tested sera from the Manhiça cohort collected during a 5-year follow-up to assess long-lived immune responses (months 8.5, 21, 33, 45, and $63, n=30$ ). Sample selection was at random and summary statistics closely matched that of the entire cohort (median age, 2.8 years and 2.5 years; male-to-female ratio, 0.93 and 0.83 ; Manhiça malaria negative-to-positive ratio, 0.17 and 0.15 ; Ilha Josina malaria negative-to-positive ratio, 2.32 and 1.41 , respectively). Individuals tested at later time points were randomly selected from those with sufficient volumes at all time points (out of $n=371$ ). Note that all serum samples were heat treated for $45 \mathrm{~min}$ at $56^{\circ} \mathrm{C}$ to inactivate any host complement proteins.

\section{Experimenter blinding}

Experimenters were blinded from the vaccine group, age group, and study site until all participants had been tested for IgG, immunoglobulin $\mathrm{M}$ (IgM), and C1q-fixation to CSP.

\section{Antigens}

The following antigens used in this study were all based on P. falciparum 3D7: recombinant CSP beginning at amino acid residue 50 that contained (NANP) 22 repeats and $(\mathrm{NVPD})_{4}$ repeats expressed in Pichia pastoris (Sanaria, Rockville, USA), synthetic (NANP) ${ }_{15}$ peptide
(NANP) representing the central repeat region of CSP (Life Tein, Hillsborough, USA), recombinant C-terminal region (CT) of CSP expressed in HEK293 cells at Burnet Institute (as described in Additional file 1: Figure S1), recombinant merozoite surface protein 2 (MSP2), and apical membrane antigen 1 (AMA1) both expressed in Escherichia coli as previously described [19, 20].

\section{Antibody detection assay}

Sera were tested by standard enzyme-linked immunosorbent assay (ELISA) to detect antibody reactivity as follows. Ninety-six-well flat bottom MaxiSorp plates (Thermo Fisher Scientific, Waltham, USA) were coated in $0.5 \mu \mathrm{g} / \mathrm{ml}$ antigen in phosphate-buffered saline (PBS) overnight at $4{ }^{\circ} \mathrm{C}$. Plates were washed (thrice with PBS-Tween20 0.05\%) using the ELx405 automated plate washer (BioTeck, Winooski, USA) and blocked with $1 \%$ casein in PBS $(w / v)$ for $2 \mathrm{~h}$ at $37^{\circ} \mathrm{C}$. Plates were washed and then incubated with human sera (tested in duplicate) in buffer $(0.1 \%$ casein in PBS, $v / v)$ for $2 \mathrm{~h}$ at room temperature (RT). Sera were tested at $1 / 4000$ dilution for IgG and IgG subclass detection and 1/500 for IgM detection (note that for the decay analysis, samples collected between M3 and M63 were tested at 1/500 for IgG subclass detection). Plates were washed, and antibody isotypes were detected using goat anti-human IgG and IgM conjugated to horseradish peroxidase (HRP, Millipore, Burlington, USA) at 1/2500 dilution in buffer for $1 \mathrm{~h}$ at RT. Plates were washed for a final time and incubated with 2,2'-azino-bis(3-ethylbenzothiazoline-6-sulfonic acid) substrate (ABTS, Thermo Fisher Scientific) shielded from light at RT. IgG and IgM reactivities were measured after 20 and $60 \mathrm{~min}$, respectively, at an optical density (OD) of $405 \mathrm{~nm}$ using the Multiskan Go plate reader (Thermo Fisher Scientific).

To detect IgG subclasses, plates were instead incubated with mouse anti-human IgG1, IgG2, IgG3, and IgG4 (Thermo Fisher Scientific), washed, and then incubated with goat anti-mouse IgG HRP (Millipore) all at $1 / 1000$ dilution in buffer for $1 \mathrm{~h}$ at RT. Plates were washed for a final time and incubated with tetramethylbenzidine substrate (TMB, Thermo Fisher Scientific) shielded from light at RT. IgG subclass reactivity was stopped after $30 \mathrm{~min}$ of incubation using $1 \mathrm{M}$ sulfuric acid, and OD was measured at $450 \mathrm{~nm}$. We have previously confirmed the specificity and sensitivity of the IgG subclass reagents used [21]. A prior report of IgG subclass responses induced by RTS,S in the phase III trial [8] used a suspension bead array method rather than ELISA. While there may be differences between these methods, prior evaluation of the two approaches for detection of malaria antibodies using a range of antigens suggested the two methods were comparable [22]. 


\section{Complement fixation assay}

Sera were tested for the ability to fix complement using the plate-based complement fixation assay as previously described [17]. Briefly, coating and blocking were conducted as described above for antibody detection. Plates were incubated with human sera (tested in duplicate) at 1/250 dilution in buffer for $2 \mathrm{~h}$ at RT (note that for the decay analysis, samples collected M3-M63 were re-tested at 1/110 dilution for C1q-fixation). Plates were washed and incubated with purified human C1q (Millipore) at $10 \mu \mathrm{g} / \mathrm{ml}$ in buffer for $30 \mathrm{~min}$, followed by washing. To detect C1q-fixation, plates were incubated with rabbit anti-C1q IgG (in-house), washed, and then incubated with goat anti-rabbit IgG HRP (Millipore) both at 1/ 2000 dilution in buffer for $1 \mathrm{~h}$ at RT. Detection antibodies were validated as described in Additional file 1: Figure S2. Plates were washed for a final time and incubated with TMB shielded from light at RT. C1q-fixation reactivity was stopped after $30 \mathrm{~min}$ of incubation using $1 \mathrm{M}$ sulfuric acid, and OD was measured at $450 \mathrm{~nm}$.

We additionally tested a random selection of $n=20$ individuals (from the RTS,S vaccine group collected at 3 M) for C5b-C9-fixation to CSP. This was conducted using the same protocol, but fresh human serum pooled from malaria-naïve donors was used as a source of complement (1/10 dilution), and rabbit anti-C5b-C9 detection antibodies were used (1/1000 dilution).

\section{Experimental controls and standardization}

To ensure accurate results, human serum samples were tested in duplicate, and those with high variability $(>25 \%)$ were re-tested or excluded (unless duplicates differed OD $<0.1$ ). Raw data were corrected for background reactivity using no-serum/blank negative controls and adjusted for plate-to-plate variation using malaria-exposed positive controls that were included on each plate. We also included malaria-naïve negative controls from Melbourne donors $(N=24)$, and test samples with an OD greater than the mean +3 standard deviations of the Melbourne controls were considered positive.

We also examined the epitope specificity of individuals and considered the ratio of NANP-to-CT IgG as equal if the variability between NANP and CT responses was < $25 \%$, which was the acceptable range for duplicate variability. Individuals who exceeded this were considered as having a NANP (ratio > 1.25) or CT-skewed (ratio < 0.75) IgG response.

\section{Statistical analysis}

For descriptive and comparative analysis, the median and interquartile range (IQR) were reported, and the following two-tailed non-parametric tests were performed where appropriate (GraphPad Prism 7; $p<0.05$ was considered significant): Mann-Whitney $U$ test, Wilcoxon matched-pairs signed-rank test, and Spearman's correlation coefficient (Rho).

Statistical models were developed to investigate (i) decay rates of complement-fixing antibodies, antibody isotypes, and IgG subclasses and (ii) the relationship between complement-fixing antibodies and different antibody types using repeated measures longitudinal data (Stata version 14, StataCorp). Given the dependency on the data from repeated measurement, multilevel modelling was used to estimate latent growth curve models exploring the subject-specific nature of the association between time and C1q-fixation, IgG subclasses, and IgM. Given the non-linear functional form of the association between time and C1q-fixation, IgG subclasses, and IgM, latent growth curve models regressed the $\log$ of C1q-fixation and IgG subclass and IgM on $\log$ time, and post-estimation non-linear equations using exponentiated model coefficients were used to provide proportional rates of change at specific time points. Latent growth curve models comprised two levels, individuals at level 2 (i.e., random intercept and coefficient for time) and their C1q-fixation, IgG subclass, and IgM response across time at level 1 (see Additional file 1: Supplementary equation 1). Nested model-based likelihood ratio statistics were used to provide statistical inference for model fit when relaxing model constraints (random effects and the functional form of fixed effects for time) and Akaike Information Criterion (AIC) and Bayesian Information Criterion (BIC) fit statistics used to inform functional form modeling across non-nested models. To further assess the fit of the estimated latent growth curve models, diagnostic plots comparing participants observed marker levels with Bayesian model-based (best linear unbiased predictions) predicted levels over time were produced and examined.

Contemporaneous (i.e., both outcome and factor variable responses from the same time period were regressed) unadjusted and adjusted longitudinal associations between C1q-fixation, IgG subclass, and IgM levels were also estimated using multilevel modelling. Level-1 error variance estimates from nested regression modeling based on these analyses were used to derive Cohen's $f^{2}$ measures of effect for each IgG subclass and IgM [23]. In these multilevel models, IgG subclass and IgM were estimated as log time-varying fixed factors and their effects unconstrained by time. In addition to these terms, both fixed and random terms for log time were also estimated and a random effect (intercept (level 2)) to account for the dependency C1q-fixation level 
measurement over-time was also estimated. Statistical inference was assessed at the $5 \%$ level.

\section{Results}

\section{RTS,S-induced anti-CSP IgG in children is predominately} IgG1 subclass

Sera collected at baseline (M0) and 30 days after receiving the final RTS,S vaccination (M3) were tested for total IgG levels to full-length CSP. Reactivity was low at baseline but significantly increased after vaccination with RTS,S in both study cohorts (OD median [IQR]: Manhiça $N=50, \mathrm{M} 0=0.020$ [0.022], and $\mathrm{M} 3=2.231$ [0.390], $p<0.001$; Ilha Josina $N=49, \mathrm{M} 0=0.030$ [0.039], and $\mathrm{M} 3=2.457$ [0.425], $p<0.001)$. In contrast, anti-CSP IgG was low at both time points in children who received the comparator non-malaria vaccine (OD median [IQR]: Manhiça $N=25, \mathrm{M} 0=0.015$ [0.020], and $\mathrm{M} 3=0.018$ [0.054], $p=0.525$; Ilha Josina $N=24, \mathrm{M} 0=0.029$ [0.037], and M3 $=0.038$ [0.045], $p=0.747$ ) (Fig. 1a).

Children vaccinated with RTS,S (sera collected at M3) were then tested for IgG subclass responses to CSP. Seropositivity was high for IgG1 (94\% and 98\%) and IgG3 (90\% and 96\%), followed by IgG2 (70\% and 86\%) and IgG4 (22\% and 51\%) in Manhiça and Ilha Josina cohorts, respectively (Fig. 1b). Overall, IgG1 reactivity was highest, followed by IgG3 and IgG2, and only low levels of IgG4 were detected among a minority of subjects. IgG1 demonstrated the strongest correlation with total IgG compared to IgG3 and IgG2, with only a weak correlation for $\operatorname{IgG} 4 \quad(\mathrm{rho}=0.875$, $\mathrm{rho}=0.689$, $\mathrm{rho}=615$, $p<0.001$ for all tests; rho $=0.208, p=0.039$, respectively) (Additional file 1: Figure S3a).

\section{RTS,S vaccination induced anti-CSP IgM}

We additionally measured IgM levels to CSP at M0 and M3 time points since the induction of IgM may contribute to complement-fixing activity and overall vaccine immunity. To date, there are little data reported on the induction of IgM by RTS,S/AS02 ${ }_{\mathrm{A}}$. There was a significant increase in IgM reactivity for children vaccinated with RTS,S in both cohorts (OD median [IQR]: Manhiça $N=50, \quad \mathrm{M} 0=0.208 \quad[0.178]$, and $\mathrm{M} 3=0.725$ [0.912], $p<0.001$; Ilha Josina $N=49, \mathrm{M} 0=0.191$ [0.227], and $\mathrm{M} 3=0.736$ [0.726], $p<0.001$ ) but not with comparator vaccine (OD median [IQR]: Manhiça $N=25, \mathrm{M} 0=0.194$ [0.198], and M3 = 0.194 [0.151], $p=0.300$; Ilha Josina $N$ $=24, \quad \mathrm{M} 0=0.225 \quad[0.200]$, and $\mathrm{M} 3=0.142$ [0.157], $p=0.089$ ) (Fig. 1c). Furthermore, anti-CSP IgM levels at M3 were significantly higher in the RTS,S vaccine group than the comparator vaccine group for both study sites $(p<0.001$ for both tests). In all RTS,S-vaccinated children $(N=99)$, anti-CSP IgG and IgM responses at M3 moderately correlated, but many demonstrated IgGhigh/IgM-low reactivity. Notably, IgM reactivity at M0

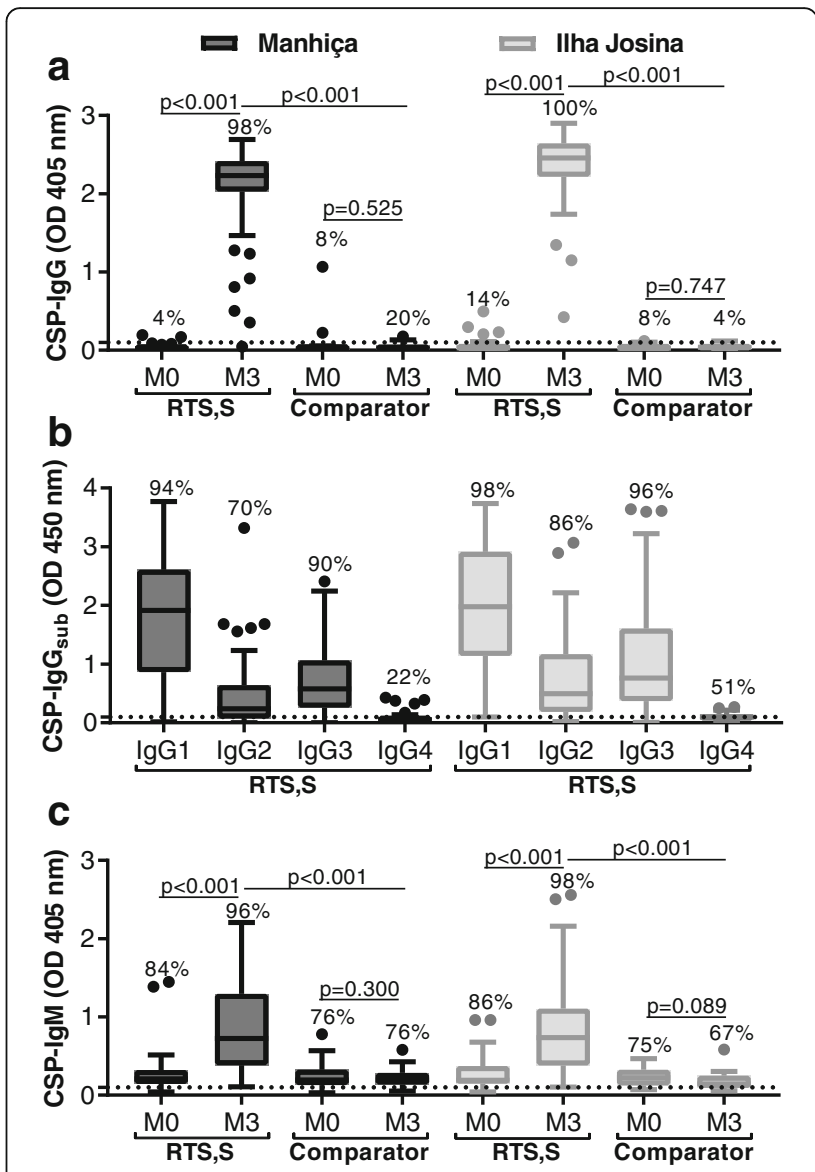

Fig. 1 RTS,S vaccine-induced IgG and IgM antibodies to CSP. Children in RTS,S and comparator vaccine groups from Manhiça (black box plots; $N=50$ and $N=25$, respectively) and Ilha Josina cohorts (gray box plots; $N=49$ and $N=24$, respectively) were tested for $\lg G(\mathbf{a})$, IgG subclasses (b), and IgM (c) to CSP. Sera collected at baseline (month $0, \mathrm{M} 0$ ) and after vaccination (month 3, M3) were tested in duplicate (note that only M3 was tested in $\mathbf{b}$ ), and the mean value was used to generate box plots whereby top, center, and bottom horizontal lines represent the 75th percentile, median, and 25th percentile, respectively; upper and lower whiskers represent the highest and lowest values within $1.5 \times 1 Q R$, respectively; and values that exceed this range are presented as dots. Malaria-naiive negative controls from Melbourne donors were used to calculate the seropositivity cutoff value (dashed lines), and the percentage of individuals above this threshold are shown. Reactivity between paired samples and unpaired samples were compared using Wilcoxon matched-pairs signed-rank test and Mann-Whitney $U$ test, respectively

and M3 was weakly correlated (rho $=0.254 ; p=0.011)$ (Additional file 1: Figure S3b).

\section{RTS,S-induced antibodies can fix and activate complement}

We have previously reported that anti-CSP antibodies can activate human complement through recruitment of C1q [17]. In this study, we detected a strong induction of functional antibodies that fix $\mathrm{Clq}$ in children 
vaccinated with RTS,S, which was observed in both study sites (OD median [IQR]: Manhiça $N=50$, $\mathrm{M} 0=0.029$ [0.054], and M3 = 1.913 [3.163], $p<0.001$; Ilha Josina $N=49, \mathrm{M} 0=0.013$ [0.038], and $\mathrm{M} 3=2.508$ [2.701], $p<0.001)$. However, this induction of complement-fixing antibodies was not seen with the comparator vaccine (Fig. 2a). RTS,S-induced antibodies could promote activation of the complement cascade, as demonstrated by the presence of complement factors involved in the terminal phase of complement activation that form the membrane attack complex (C5b-C9). Detection of the C5b-C9 complex significantly correlated with $\mathrm{C} 1 \mathrm{q}$-fixation $(n=20$, rho $=0.937 ; p<0.001)$ (Fig. 2b).

\section{Complement-fixing antibodies target the central repeat and C-terminal regions of CSP}

To investigate the targets of functional antibodies induced by RTS,S, we first measured antibody reactivity to NANP and CT antigens, which represented the central repeat and C-terminal regions of CSP, respectively (Fig. 3a, b). Compared to baseline, children vaccinated with RTS,S had significantly higher levels of IgG to both regions of CSP ( $p<0.001$ for all tests), whereas IgM was mostly NANP-specific (NANP, $p<0.001$ for all tests; CT, $p=0.032$ and $p=0.177$ for Manhiça and Ilha Josina cohorts, respectively).

Interestingly, IgG reactivity to NANP and CT significantly correlated with C1q-fixation to full-length CSP, suggesting both regions were involved in the functional activity (rho: NANP $=0.727$ and $\mathrm{CT}=0.676 ; p<0.001$ for both tests) (Fig. 3c). Indeed, we confirmed that antibodies to each region of CSP could directly fix C1q using specific antigen constructs, although complementfixing activity was greater against NANP than $\mathrm{CT}$, and correlated more strongly with C1q-fixation to full-length CSP (OD median [IQR]: NANP $=1.25$ [2.34] and $\mathrm{CT}=0.14$ [0.24]; rho: $\mathrm{NANP}=0.926$ and $\mathrm{CT}=0.730$; $p<0.001$ for both tests) (Fig. 3d).

We then compared antibody responses between children who had high or low levels of complement-fixing antibodies to CSP (defined based on the median: high $N$ $=50$, OD range 2.03 to 4.00 ; low $N=49$, OD range 0.02 to 1.97). Notably, children with high C1q-fixing antibodies had substantially higher levels of IgG to both NANP and CT and higher levels of IgM to NANP (IgG: NANP $p<0.001$, CT $p<0.001$; IgM: NANP $p<0.001$, CT $p=0.038$ ) (Additional file 1: Figure S4). We further examined the epitope specificity using heat maps and found high variability among individuals with respect to IgG and IgM levels to the different regions (Fig. 4a). We explored different approaches to identify potential influencing factors for complement fixation activity. Linear regression for anti-NANP IgG with the additional inclusion of anti-CT IgG did not substantially improve the fit of the model overall compared to IgG to NANP alone, and we found no significant linear relationship between epitope-specific IgM by linear regression (Additional file 1: Table S1). Given the observed variability in IgG responses to the NANP and CT regions, we calculated the ratio of NANP-to-CT IgG, which was used to categorize children in equal, NANP-skewed, or CT-skewed IgG epitope profiles (defined by ratios of 0.75 to $<1.25,>1.25$, and $<0.75$, respectively) (Fig. 4b). Interestingly among the high complement-fixing group, a greater proportion had relatively equal levels of IgG to both NANP and CT (63\%), while some were NANP-skewed (27\%) and fewer CT-skewed (10\%). For children with low C1q-fixing antibodies, all three epitope profiles were equally observed (33\% each) (Fig. 4c). This
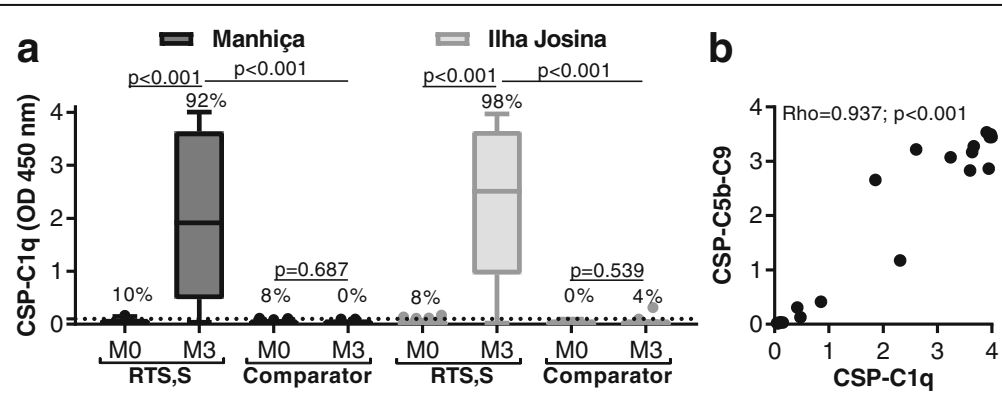

Fig. 2 RTS,S vaccine-induced antibodies promote complement fixation to CSP. a Children in RTS,S and comparator vaccine groups from Manhiça (black box plots; $N=50$ and $N=25$, respectively) and Ilha Josina cohorts (gray box plots; $N=49$ and $N=24$, respectively) were tested for C1qfixation to CSP. Sera collected at baseline (month 0, M0) and after vaccination (month 3, M3) were tested in duplicate, and the mean value was used to generate box plots whereby top, center, and bottom horizontal lines represent the 75th percentile, median, and 25th percentile, respectively; upper and lower whiskers represent the highest and lowest values within $1.5 \times I Q R$, respectively; and values that exceed this range are presented as dots. Malaria-naive negative controls from Melbourne donors were used to calculate the seropositivity cutoff values (dashed lines), and the percentages of individuals above this threshold are shown. Reactivity between paired samples and unpaired samples were compared using Wilcoxon matched-pairs signed-rank test and Mann-Whitney $U$ test, respectively. b Random selection of children in the RTS,S vaccine group from Manhiça cohort $(n=20$, M3) were tested for C5b-C9-fixation to CSP, and the mean of duplicates was graphed as scatter plots 

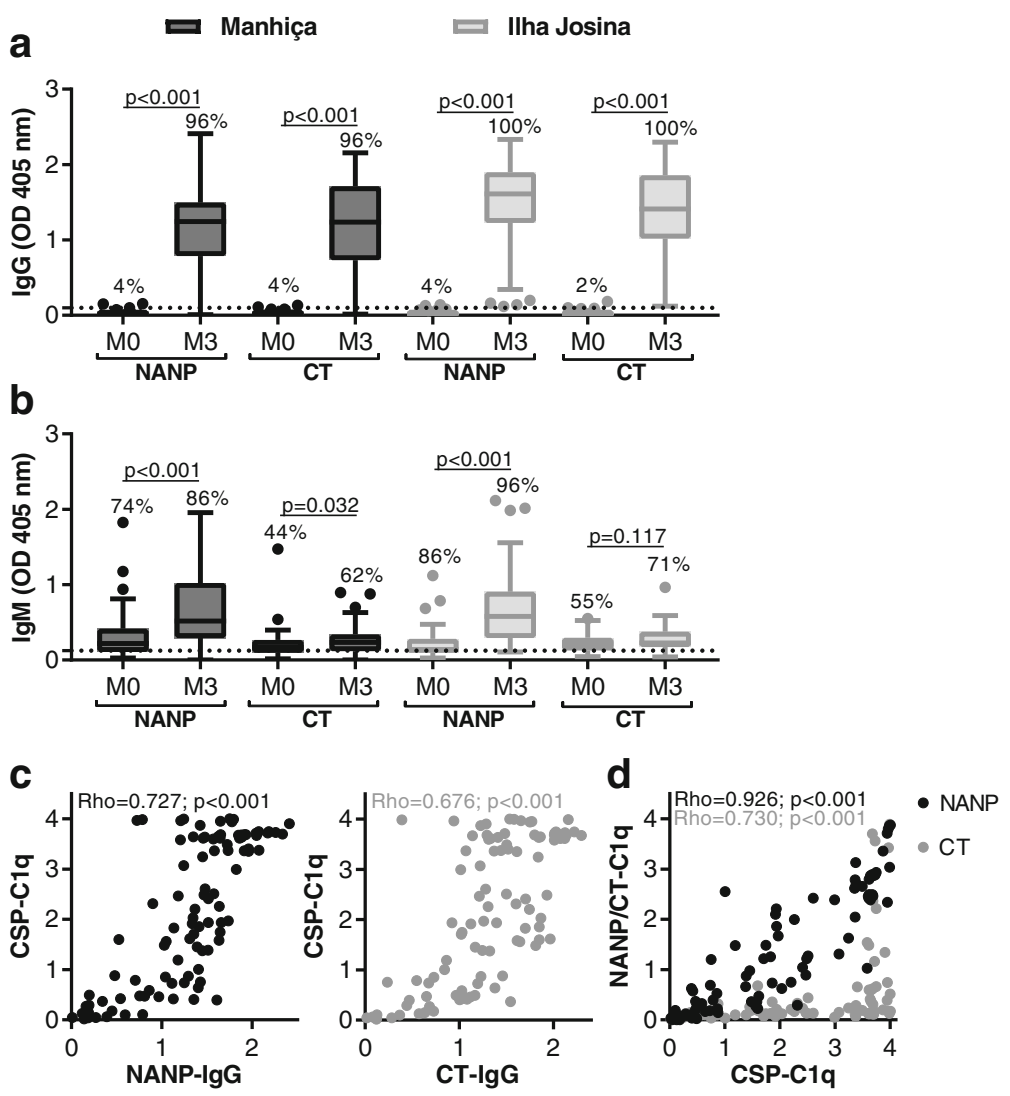

Fig. 3 Functional complement-fixing antibodies target the central repeat and C-terminal regions of CSP. Children in RTS,S vaccine group from Manhiça (black box plots; $N=50$ ) and llha Josina cohorts (gray box plots; $N=49$ ) were tested for $\lg G(\mathbf{a})$ and $\operatorname{lgM}(\mathbf{b})$ to NANP and $C T$ regions of CSP. Sera collected at baseline (month $0, \mathrm{MO}$ ) and after vaccination (month 3, M3) were tested in duplicate, and the mean value was used to generate box plots whereby top, center, and bottom horizontal lines represent the 75th percentile, median, and 25th percentile, respectively; upper and lower whiskers represent the highest and lowest values within 1.5× IQR, respectively; and values that exceed this range are presented as dots. Malaria-naiive negative controls from Melbourne donors were used to calculate the seropositivity cutoff values (dashed lines), and the percentages of individuals above this threshold are shown. Reactivity between paired samples was compared using Wilcoxon matched-pairs signed-rank test. c, d Children in RTS,S vaccine group from Manhiça and Ilha Josina cohorts ( $N=99, M 3)$ were tested for C1q-fixation to CSP, NANP, and CT, and the values were plotted compared to lgG reactivity $(c)$ and C1q fixation to CSP, NANP, and CT were correlated (d)

suggests that IgG reactivity to both regions may be favorable for C1q-fixation to full-length CSP.

\section{Poor induction of functional antibodies in children with higher malaria exposure and blood-stage immunity}

To evaluate the potential effect of malaria exposure on the induction of complement-fixing antibodies, we compared RTS,S-induced functional antibodies (sera collected at M3) in younger and older age groups (12-24 and 24-60 months, respectively) and between our two different study sites (Additional file 1: Figure S5a). Children in the Manhiça cohort demonstrated no relationship between age and C1q-fixation to CSP (younger $n=11$ and older $n=39, p=0.579 ; \quad$ rho $=-0.121$, $p=0.403)$. For the Ilha Josina cohort, which had a substantially higher level of malaria transmission than Manhiça, younger children had significantly higher levels of C1q-fixing antibodies (younger $n=23$ and older $n=26$, $p<0.001)$, and age negatively correlated with C1qfixation (rho $=-0.575, p<0.001$ ). Similar age associations were also observed for C1q-fixation to NANP (Fig. 5a) as well as anti-CSP IgG and IgG subclass responses. However, anti-CSP IgM was comparable between the age groups for the Ilha Josina cohort but was interestingly higher in older children for the Manhiça cohort (Additional file 1: Figures S5b-d).

The Ilha Josina study site had a higher level of malaria transmission intensity than Manhiça, indicating that age associations may be related to malaria exposure. To investigate, we measured antibody responses to wellcharacterized blood-stage antigens, MSP2 and AMA1, which are established biomarkers of malaria exposure [24] (Fig. 5b). The relationship between age and blood-stage antibodies was weak for the Manhiça cohort (MSP2 $p=0.112$ and AMA1 $p=0.009$; correlation with age, MSP2 rho $=255, p=0.074$, and AMA1 rho $=0.302$, 


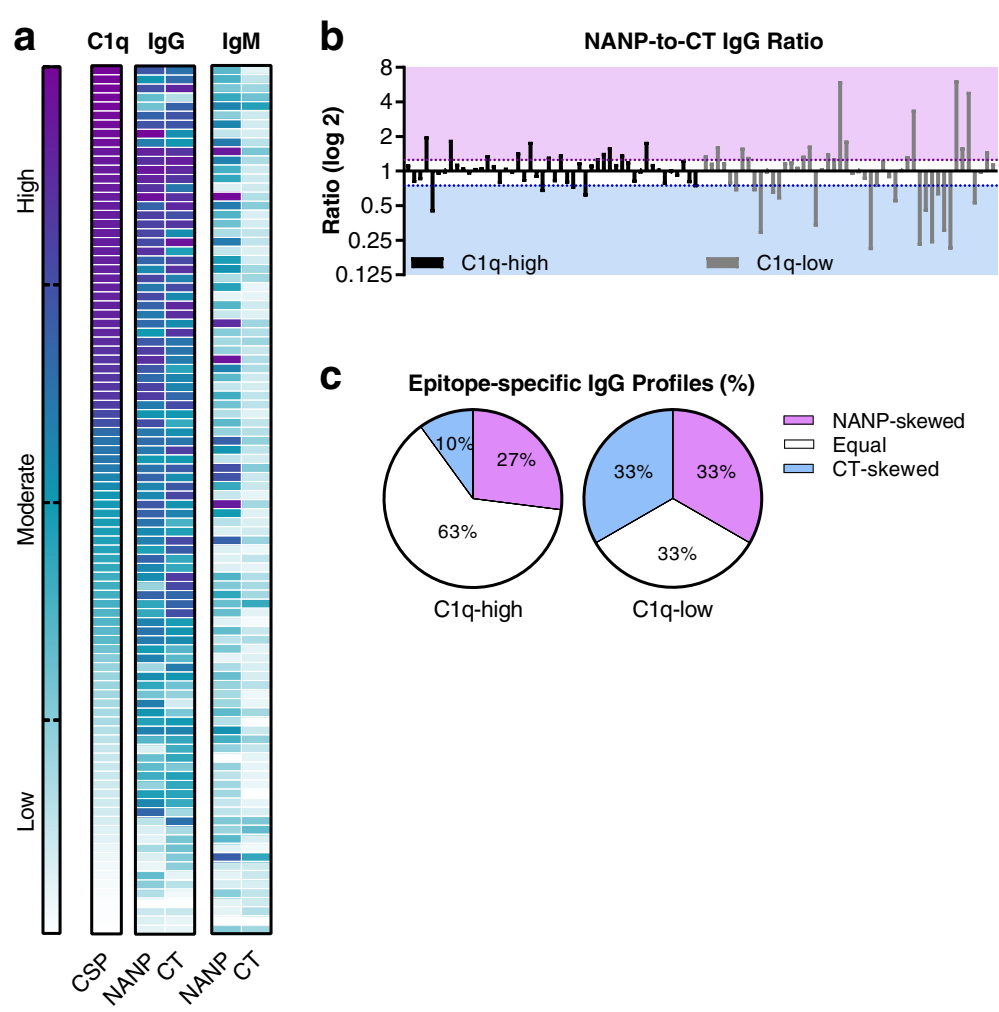

Fig. 4 High variability among RTS,S vaccine-induced IgG targeting the central repeat and C-terminal regions of CSP. Children in RTS,S vaccine group from Manhiça and Ilha Josina cohorts ( $N=99,3 \mathrm{M}$ ) were tested for lgG to NANP and CT and C1q-fixation to CSP, and the values were used for the following analysis. a Heat map of children arranged in descending (top to bottom) order of Clq-fixation (left), corresponding lgG to NANP and $C T$ (middle), and for comparison IgM to NANP and CT (right). b Variability between epitope specificity was quantified by calculating the ratio of NANP-to-CT IgG. Children with low variability were considered to have equal reactivity to NANP and CT (ratio between 0.75 and 1.25 shown in white), and children exceeding this range were considered to have a NANP- or CT-skewed response (ratio $>1.25$ shown in purple and ratio < 0.75 shown in blue, respectively). Children were arranged in descending order of C1q-fixation (left to right), whereby those in the top quantile are in black bars (C1q-high, OD range 2.03 to 4.00) and those in the bottom quantile are in gray bars (C1q-low, OD range 0.02 to 1.97). c Pie charts representing the percentage of children with the following epitope-specific lgG profiles from C1q-high and C1q-low groups: NANP-skewed, equal, and CT-skewed

$p=0.033$ ) but strong for the Ilha Josina cohort (MSP2 $p<0.001$ and AMA1 $p<0.001$; correlation with age, MSP2 rho $=0.595, p<0.001$, and AMA1 rho $=0.605$, $p<0.001)$. Furthermore, in the Ilha Josina cohort, C1q-fixation to CSP negatively correlated with IgG to MSP2 and AMA1 (rho $=-0.453, p=0.001$; rho $=-0.443$, $p=0.002$, respectively). Collectively, these data suggest that increased malaria exposure negatively impacts the induction of functional immunity by RTS,S immunization.

\section{Functional antibodies are poorly sustained after RTS,S vaccination}

To assess long-term RTS,S-induced immunity, we examined a random selection of children from the Manhiça cohort $(n=30)$ with samples available at months $3,8.5$, $21,33,45$, and 63 (5-year follow-up). Maximal C1q-fixation responses were observed at M3, which then significantly declined by M8.5 (OD median, 2.363 and 0.174 , respectively; $p<0.001$ ) (Fig. 6a and Additional file 1: Figure S6). Sera were re-tested at a higher concentration (1/110 dilution), and a similar result was obtained. Interestingly, a small number of individuals did maintain complement-fixing activity for a longer period (Additional file 1: Figure S6). Antibody concentration is known to effect complement activity, and therefore, the decline in $\mathrm{C} 1 \mathrm{q}$-fixation responses may have been due to antibody levels being below the required functional threshold (Additional file 1: Figure S7).

IgG and IgM responses to CSP also waned over time, although this did not appear as marked as the loss of C1q-fixing antibodies (Fig. 6b). Given that IgG subclass strongly influences antibody function, we examined the decay of each IgG subclass response with respect to the decline in functional C1q-fixing activity (Fig. 6c). IgG1 


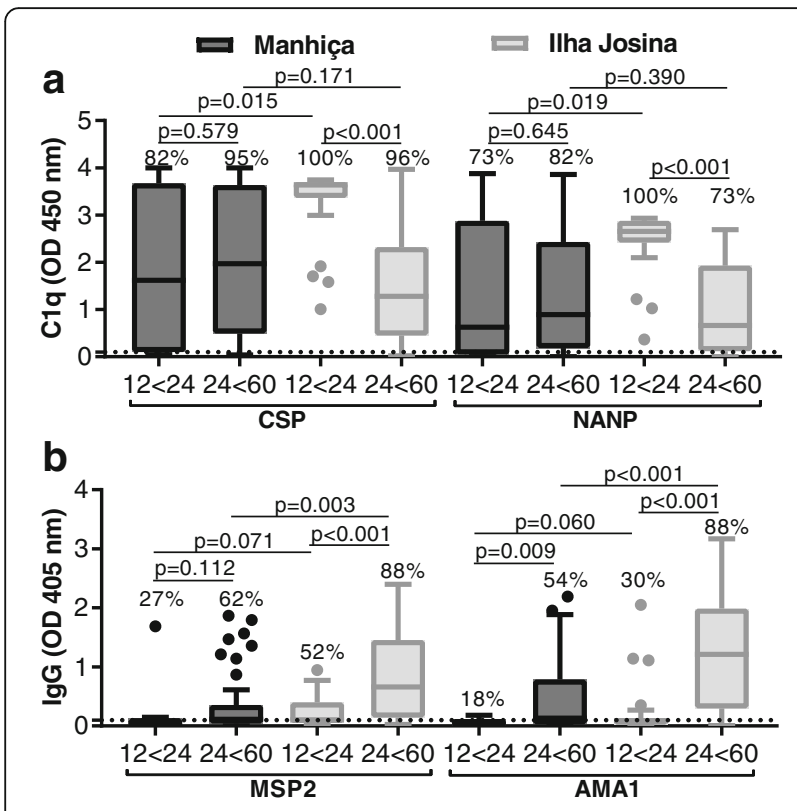

Fig. 5 Relationship between age and immunity. Children in RTS,S vaccine group from Manhiça (black box plots) and llha Josina cohorts (gray box plots) were categorized into younger (12 to 24 months; Manhiça $n=11$ and Ilha Josina $n=23$, respectively) and older (24 to 60 months; Manhiça $n=39$ and Ilha Josina $n=26$, respectively) age groups. Sera collected after vaccination (month 3, M3) were tested for C1q-fixation to CSP and NANP (a) and lgGreactivity to blood-stage antigens MSP2 and AMA1 (b). Samples were tested in duplicate, and the mean value was used to generate box plots for samples stratified by age group. Top, center, and bottom horizontal lines represent the 75th percentile, median, and 25th percentile, respectively; upper and lower whiskers represent the highest and lowest values within $1.5 \times \mathrm{IQR}$, respectively; and values that exceed this range are presented as dots. Malaria-naïve negative controls from Melbourne donors were used to calculate the seropositivity cutoff values (dashed lines), and the percentages of individuals above this threshold are shown. Reactivity between unpaired samples was compared using Mann-Whitney $U$ test

and IgG3 responses both declined substantially over time, consistent with the decline in complement-fixing antibodies.

\section{Modeling the decay of complement-fixing antibodies}

Determining the decay rate of specific antibody types is important for understanding the duration of vaccine-induced immunity and informs how this may be improved in the future. Therefore, we developed methods to estimate the decay rates of complement-fixing antibodies, IgG subclasses, and IgM, using latent growth curve modeling (Table 1). Antibody decay followed a largely exponential decay, and a $\log$ of the data was used to normalize the data. Descriptively, the rate of decline of IgG1, IgG2, and IgG3 was similar, whereas IgM decay was slower. IgG4 was estimated to have a slow decay rate; however, the levels of IgG4 were very low overall. The rate of decay of complement-fixing antibodies was higher than that seen for total IgG. The half-life of

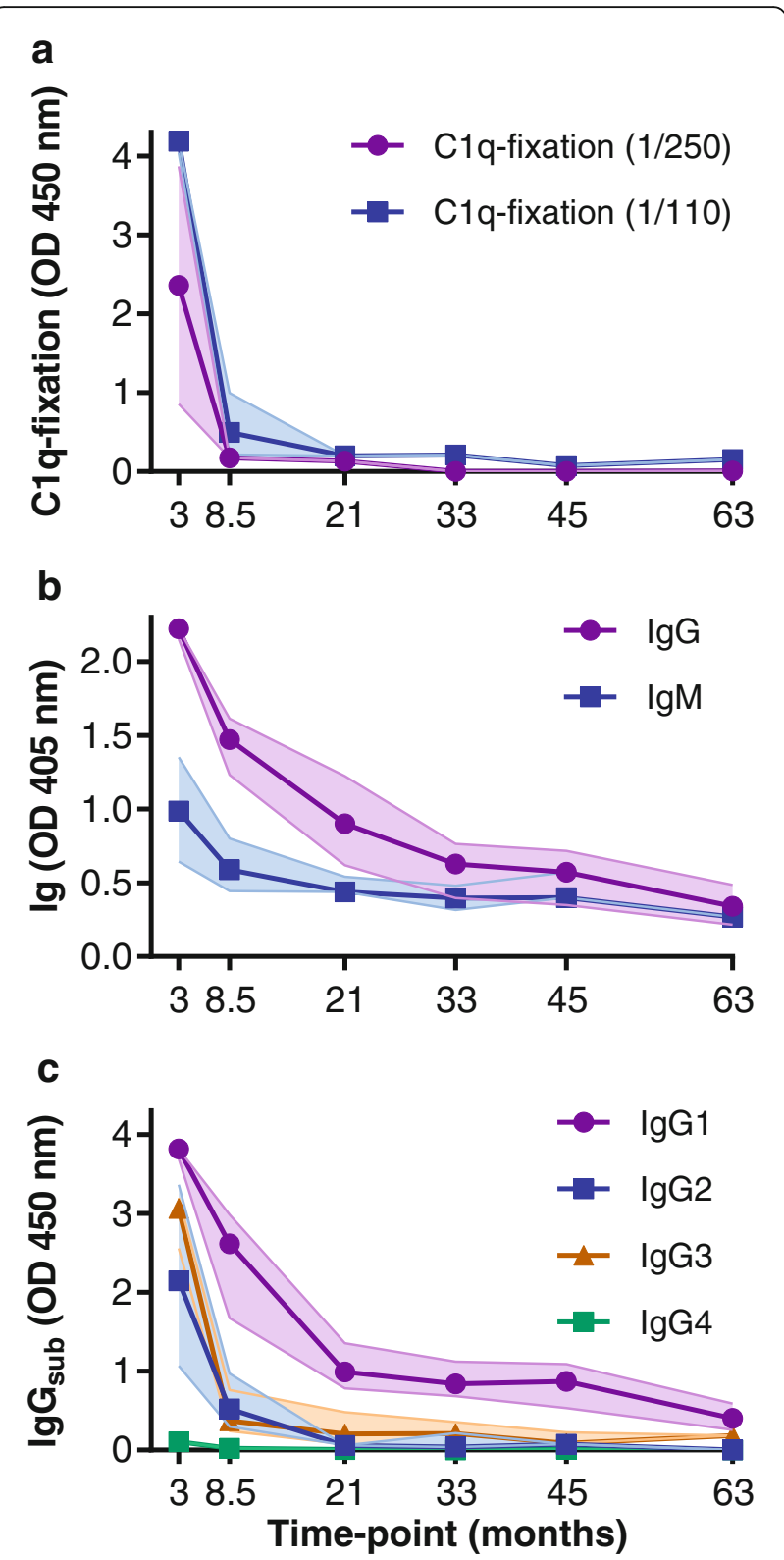

Fig. 6 RTS,S vaccine-induced immunity declines over time. A random selection of children vaccinated with RTS,S (Manhiça cohort, $n=30$ ) was tested for C1q-fixation (a), $\operatorname{lgG} / \operatorname{lgM}(\mathbf{b})$, and $\operatorname{lgG}$ subclasses (c) to CSP at months 3, 8.5, 21, 33, 45, and 6. Note that due to low reactivity, C1q-fixation was re-tested at a higher dilution of $1 / 110$, in addition to $1 / 250$, to confirm results. Samples were tested in duplicate, and the median and $95 \% \mathrm{Cl}$ of the median from each time point group are shown by the symbol and shaded area, respectively

complement-fixing antibodies was relatively short (5.2 [3.86.5] months) compared to that of IgG1 (8.4 [6.0-10.8] months), IgG2 (10.8 [5.70-15.9] months), and IgG3 (8.6 [6.2-10.9] months) subclass responses.

To better understand the factors contributing to the decline in complement-fixing antibodies over time, we 
Table 1 Associations between complement fixation, antibody responses, and time using latent growth curve modeling ( $n=$ 30)

\begin{tabular}{llll}
\hline Outcome $^{\mathrm{a}}$ & $b^{\mathrm{b}}($ s.e. $)$ & $95 \% \mathrm{Cl}$ & $p$ value $^{c}$ \\
\hline $\log \mathrm{Clq}$ & $-0.42(0.03)$ & $-0.49,-0.36$ & $<0.001$ \\
$\log \operatorname{lgG} 1$ & $-0.33(0.02)$ & $-0.37,-0.28$ & $<0.001$ \\
$\log \lg \mathrm{g} 2$ & $-0.30(0.02)$ & $-0.33,-0.26$ & $<0.001$ \\
$\log \operatorname{lgG} 3$ & $-0.32(0.02)$ & $-0.36,-0.28$ & $<0.001$ \\
$\log \operatorname{lgG} 4$ & $-0.03(0.004)$ & $-0.04,-0.02$ & $<0.001$ \\
$\log \lg M$ & $-0.12(0.02)$ & $-0.16,-0.09$ & $<0.001$ \\
\hline
\end{tabular}

${ }^{a}$ Effects for each factor represent separate linear mixed modeling (LMM) analyses where the natural log of $\mathrm{C} 1 \mathrm{q}$-fixation and each antibody response is regressed on the natural log of time (per month). These LMMs applied a random intercept for study participant, random slope for log time with an unstructured covariance parameter specified for the correlation between the random effects

${ }^{b}$ Regression coefficient $(b)$ and standard error (s.e.) represent the percent change in C1q-fixation or antibody response for a percent increase in time 'Probability values based on Wald statistics

developed a model to determine which antibodies most strongly correlated with declining complement-fixing activity using the repeated measures data. We undertook nested multivariable mixed modeling to estimate the unique variance of complement-fixing antibodies by each antibody response type (Table 2). The analysis indicated that longitudinal complement-fixation responses were most strongly independently associated with IgG1 $\left(f^{2}=0.38\right.$, Wald $\left.\chi^{2}(2)=55.3 ; p<.001\right)$ and there was also a significant correlation with IgG3 $\left(f^{2}=0.18\right.$, Wald $\chi^{2}(2)$ $=29.5 ; p<.001)$. There was no significant association with IgG2, IgG4, or IgM.

\section{Discussion}

Knowledge of the induction and maintenance of functional immune responses by RTS,S is valuable for strategically improving vaccine design and delivery to generate a highly efficacious and longer-lasting malaria vaccine. Here, we investigated RTS,S-induced antibody responses in children and present new evidence of a functional mechanism that may contribute to vaccineinduced immunity. We show that RTS,S-induced anti-CSP antibodies were predominantly IgG1, and there was also a substantial induction of IgG3, IgG2, and IgM. Antibodies among vaccinated children could strongly fix complement on the whole, but functional responses did vary among individuals. Our data suggest that antibodies targeting both the central repeat and C-terminal regions of CSP are important for complement fixation. Furthermore, functional antibodies were poorly induced in older children with greater malaria exposure, and functional antibodies were poorly maintained after vaccination. This decline in complement-fixing antibodies was largely due to a decline in IgG1 and to a lesser extent IgG3. These findings highlight the diversity of RTS,S-induced
Table 2 Associations between antibody responses and complement fixation activity over time using linear mixed modeling $(n=30)$

\begin{tabular}{lllll}
\hline Factor $^{\mathrm{a}}$ & $b^{\mathrm{b}}$ (s.e.) & $95 \% \mathrm{Cl}$ & $p$ value $^{\mathrm{c}}$ & $p^{2 \mathrm{~d}}$ \\
\hline IgG1 & & & & 0.38 \\
$\quad$ Linear term & $1.10(0.16)$ & $0.78,1.41$ & $<0.001$ & \\
$\quad$ Interaction term & $-0.28(0.05)$ & $-0.38,-0.18$ & $<0.001$ & \\
IgG2 & & & & 0.02 \\
$\quad$ Linear term & $0.11(0.13)$ & $-0.14,0.37$ & 0.388 & \\
$\quad$ Interaction term & $-0.01(0.05)$ & $-0.10,0.08$ & 0.805 & \\
IgG3 & & & & 0.18 \\
Linear term & $0.54(0.15)$ & $0.24,0.83$ & $<0.001$ & \\
Interaction term & $-0.07(0.05)$ & $-0.18,0.03$ & 0.177 & \\
IgG4 & & & & 0.02 \\
$\quad$ Linear term & $0.21(0.86)$ & $-1.47,1.90$ & 0.802 & \\
Interaction term & $0.07(0.31)$ & $-0.53,0.68$ & 0.808 & \\
IgM & & & & 0.03 \\
Linear term & $-0.21(0.18)$ & $-0.57,0.38$ & 0.233 & \\
Interaction term & $-0.02(0.07)$ & $-0.11,0.15$ & 0.792 & \\
\hline
\end{tabular}

a Linear mixed modeling (LMM) analyses where the natural log of C1q-fixation was regressed on the natural log of antibody responses (linear term) conditioning on other antibody response factors to provide an independent association. This LMM model included a term for the natural log of time (not shown) and relaxed the constraint of a consistent association between C1qfixation and antibody responses across time (interaction term). The LMMs applied a random intercept for study participant and random slope for time ${ }^{\mathrm{b}}$ Regression coefficient $(b)$ and standard error (s.e.) represent the percent change in participant $\mathrm{C} 1 \mathrm{q}$-fixation level for a percent increase in antibody responses

'Probability values based on Wald statistics

${ }^{\mathrm{d}}$ Cohen's $f^{2}$ represents the ratio of the unique variance explained by a specific antibody response factor to the variance explained by an intercept-only model. Higher values indicate a stronger effect

immune responses in malaria-exposed populations, demonstrate a new functional mechanism of vaccineinduced antibodies, and shed some light on the maintenance and decay of vaccine immunity. Our findings suggest that generating higher levels of complementfixing antibodies among a greater proportion of children, and inducing responses that are durable over time, may contribute to greater vaccine efficacy and durability.

IgG1 and IgG3 subclasses have the highest complement-fixing activity, whereas IgG2 and IgG4 have little or no activity [25]. RTS,S/AS02 ${ }_{\mathrm{A}}$ strongly induced anti-CSP IgG1 followed by IgG3 and IgG2 in children aged 1-4 years. Similar findings showing a predominant IgG1 and IgG3 response were recently reported for a subset $(n=195)$ of subjects from the phase III RTS,S/ $\mathrm{ASO1}_{\mathrm{B}}$ vaccine trial of infants and young children (6-12 weeks and 5-17 months). A higher ratio of cytophilic antibodies (IgG1 and IgG3) to non-cytophilic antibodies (IgG2 and IgG4) was associated with vaccine-induced protection [8]. Therefore, we propose that one way in which RTS,S-induced cytophilic antibodies may confer 
protection is by interacting with human complement, a mechanism that has been previously associated with protection in studies of naturally acquired immunity to sporozoites in children [17]. The $\mathrm{ASO}_{\mathrm{B}}$ and $\mathrm{ASO2}_{\mathrm{A}}$ adjuvants both contain TLR4 agonist MPL and the saponin QS-21, but $\mathrm{AS} 1_{\mathrm{B}}$ is a liposome-based adjuvant whereas $\mathrm{ASO2}_{\mathrm{A}}$ is an oil-in-water emulsion [26]; RTS,S administered with either adjuvant appears to induce similar IgG subclass profiles in malaria-exposed children. In the phase III study, post-vaccination levels of IgG2 and IgG4, but not IgG1 and IgG3, to CSP were significantly higher in the high malaria transmission site compared to the low malaria transmission site [8]. It is noteworthy that studies in malaria-naïve adults found RTS,S to predominately induce IgG1 and IgG2 only [27-29], which demonstrates that immunogenicity can substantially differ in malaria-exposed populations compared to malaria-naïve individuals in non-endemic countries. Such differences are poorly understood but require a greater understanding, particularly because IgG3 is a potent mediator of complement fixation and activation. The use of adjuvants or vaccine regimens that increase IgG3 and reduce IgG2 induction is likely to lead to responses with greater complement-fixing activity and potentially greater efficacy.

Complement activity can also be mediated by IgM antibodies. Interestingly, anti-CSP IgM seropositivity was moderate at baseline, although functional $\mathrm{Clq}$ fixation responses were only apparent after RTS,S vaccination when IgM (and IgG) had significantly increased. Modeling the decay of antibodies over time suggests IgM is not a major mediator of complement-fixing activity, and this was instead largely mediated by IgG1 and IgG3. The role of IgM in immunological memory is not well established, but a recent study demonstrated that IgM memory B cells were long-lived and involved in secondary responses using a murine model of malaria [30], and IgM responses remain present even in those with extensive malaria exposure [31].

Complement activity is also influenced by epitopespecificity [32-34]. We found that RTS,S-induced antibodies were most potent at fixing complement to the central repeat region of CSP, but antibodies to the C-terminal region could also fix complement. Interestingly, children with higher complement-fixing antibodies tended to have equal levels of IgG to both CSP regions, whereas those with low functional antibodies were more frequently epitope-skewed. Therefore, antibodies to both regions may better promote immune complex formation that leads to complement fixation and activation. Overall, there were highly diverse IgG epitope profiles among children. In field evaluations of RTS,S, only IgG to the central repeat region have been typically measured and reported. This is likely because RTS,S-induced antibodies to the central repeat region, but not the C-terminal region, show some association with protection in studies of healthy malaria-naïve adults [10, 29, 35-37]. However, the relationship between protection and repeat-specific antibodies has been inconsistently reported in field evaluations of malaria-exposed children and infants $[18,38,39]$. A recent study found that antibodies to both regions of CSP, that were of a specific IgG subclass, were associated with protection in the phase III clinical trial of RTS,S/AS01 $\mathrm{B}$ [8]. Additionally, the central repeat region is considered immunodominant as it is a major target of antibodies induced by whole irradiated attenuated sporozoite vaccines and natural malaria exposure $[40,41]$, and repeat-specific antibodies can block sporozoite infectivity in vitro [42]. However, antibodies to non-repeat regions are also naturally acquired and have demonstrated inhibitory activity in vitro [43-47]. Taken together, our data support the importance of antibodies to the central repeat region of CSP, but also encourage further investigation of antibody responses to the $\mathrm{C}$-terminal region, particularly because repeat-specific antibodies alone are a poor correlate of protection.

RTS,S-induced antibodies strongly fixed complement to CSP, but overall functional activity among vaccinated children markedly declined by M8.5. Although total IgG remained moderate at this time, reactivity may have dropped below the threshold required to detect functional activity using our methods, particularly because antibody density is known to influence complement activity, as multiple $\mathrm{C} 1 \mathrm{q}$ monomers (six in total) bind neighboring IgG molecules to initiate the classical complement pathway [32]. Our statistical modeling indicated that the rapid decay of complement-fixing antibodies was mostly explained by the decline in IgG1 and to a lesser extent IgG3, likely because both subclasses can potently fix complement and because IgG1 was the predominant subclass induced by vaccination. Perhaps, if RTS,S induced greater levels of IgG3 that were above the antibody threshold needed for functional activity and were more durable, complement-fixing antibody responses may have better maintained after vaccination. Including measures over time enabled a better understanding of the relationships between specific antibody types and complement fixation than analysis performed at a single cross-sectional time point. While the decay post-immunization of IgG to the central repeat region has been reported [48], there are no data on the decay of functional antibodies, IgG subclasses, or IgM. Additionally, no malaria vaccine studies have reported the relationship between IgG or IgM and functional antibodies over time. Therefore, our new statistical methods developed for this study may be valuable for understanding these responses in other RTS,S trials and studies of 
other malaria vaccines. It is possible that functional antibodies, IgG subclasses, and IgM have different responses and kinetics after booster immunizations. The decay of complement-fixing antibodies was broadly consistent with the decline in RTS,S vaccine efficacy for this trial. Statistical analyses estimated that initial efficacy against clinical malaria was $\sim 30 \%$ in the first $4-5$ months but quickly waned to limited efficacy $18-30$ months after vaccination. In our studies, some children retained significant complement-fixing antibodies at M8.5, which may contribute to some continuing vaccine efficacy. Our findings suggest these questions warrant investigation in the phase III trials to better understand the efficacy and durability of RTS,S.

The present study was conducted in a malariaendemic setting, and therefore, children will have varying degrees of malaria exposure and naturally acquired immunity. Older children in the higher malaria transmission site, Ilha Josina, had significantly lower levels of complement-fixing antibodies. This was also observed for total IgG to CSP, but the effect was not as pronounced. Older children also had higher levels of antibodies to blood-stage antigens, and this inversely correlated with vaccine-induced anti-CSP antibodies, which has been previously reported [49, 50]. Interestingly, these trends were only clear in the Ilha Josina study site, where transmission intensity was approximately tenfold higher than the Manhiça site. These findings suggest that age and higher levels of malaria exposure negatively impact on the induction of functional antibodies by the RTS,S vaccine. This is a significant finding that has implications for generating immunogenic and efficacious malaria vaccines in high transmission zones. The biological basis for this effect is not known but could be due to $\mathrm{T}$ or $\mathrm{B}$ cell exhaustion from repeated exposure [51], or naturally acquired immunity could be interfering with the induction of vaccine immunity. Understanding this issue is a priority for further research.

\section{Conclusions}

We have provided a detailed characterization of RTS,Sinduced antibody responses in malaria-exposed children and identified a new functional antibody activity induced by RTS,S. This is an important finding as recent studies demonstrated that complement fixation by antibodies could inhibit sporozoite traversal and lead to sporozoite cell death [16, 17], suggesting that RTS,S-induced immunity may function, in part through complement fixation. Our data demonstrates highly diverse patterns of epitope specificity among children and raises the potential role of the C-terminal region of CSP in functional immunity, in addition to antibodies targeting the NANP region. This finding calls for further examination of how antibodies to the $\mathrm{C}$-terminal region may co-operatively promote antibody function, such as complement activation. Complement-fixing antibodies were generally relatively short-lived and were less effectively induced in older children with higher malaria exposure, which could be important for vaccine implementation in locations with high malaria transmission intensity and should be further evaluated. Furthermore, we developed statistical methods to investigate antibody decay and relationships over time post-vaccination; these approaches could be highly valuable in future vaccine trial evaluation, especially as a tool to investigate the determinants of vaccine longevity and inform strategies to improve this. Our findings support future investigation of the large phase III trials to determine whether complement fixation is a valuable correlate of protective immunity and advance the development of more efficacious and long-lasting vaccines.

\section{Additional file}

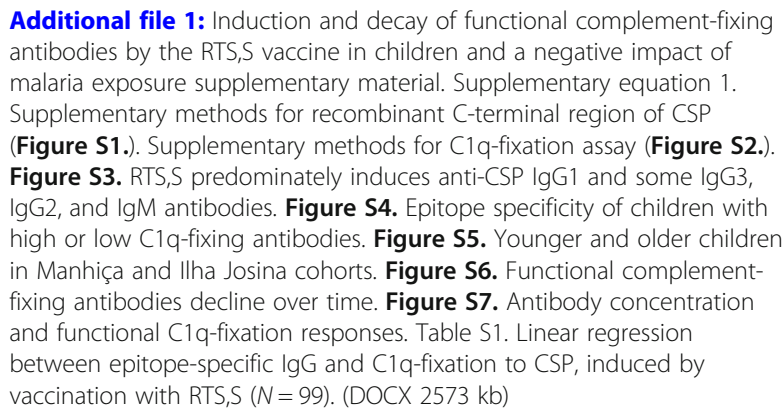

Additional file 1: Induction and decay of functional complement-fixing antibodies by the RTS,S vaccine in children and a negative impact of malaria exposure supplementary material. Supplementary equation 1. Supplementary methods for recombinant C-terminal region of CSP (Figure S1.). Supplementary methods for C1q-fixation assay (Figure S2.). Figure S3. RTS,S predominately induces anti-CSP IgG1 and some lgG3, $\lg G 2$, and IgM antibodies. Figure S4. Epitope specificity of children with high or low C1q-fixing antibodies. Figure S5. Younger and older children in Manhiça and Ilha Josina cohorts. Figure S6. Functional complementfixing antibodies decline over time. Figure S7. Antibody concentration and functional C1q-fixation responses. Table S1. Linear regression between epitope-specific lgG and C1q-fixation to CSP, induced by vaccination with RTS,S $(N=99)$. (DOCX $2573 \mathrm{~kb})$

\section{Abbreviations}

ABTS: 2,2'-Azino-bis(3-ethylbenzothiazoline-6-sulfonic acid); AIC: Akaike Information Criterion; AMA1: Apical membrane antigen 1; BIC: Bayesian Information Criterion; CSP: Circumsporozoite protein; CT: Construct representing the C-terminal region of CSP; ELISA: Enzyme-linked immunosorbent assay; HRP: Horseradish peroxidase; IgG: Immunoglobulin G; IgM: Immunoglobulin M; IQR: Interquartile range; M0: Month 0; M3: Month 3; MSP2: Merozoite surface protein 2; NANP: Peptide representing the central repeat region of CSP; OD: Optical density; PBS: Phosphate-buffered saline; RT: Room temperature; TMB: Tetramethylrhodamine

\section{Acknowledgements}

We thank all children and parents/guardians who participated in this study, all CISM and ISGlobal staff who facilitated the Mozambican RTS,S/ASO2 A Phase Ilb clinical trial, and GSK Biologicals for the conduct of the clinical trial. We thank Pedro Alonso who was involved in all phases of the clinical trial. We thank Joe Campo for managing the samples and databases used for all immunogenicity studies, particularly the M63 cross-sectional follow-up, as well as Caterina Guinovart, Eusebio Macete, Pedro Aide and Augusto Nhabomba who were involved in the clinical trials. We also thank Nana Aba Williams and Núria Díez for coordination and management, Ruth Aguilar, Gemma Moncunill and Clarissa Valim for their inputs in the design of this study, Marta Vidal for preparing samples for shipment and Laura Puyol for arranging shipment.

\section{Funding}

This work was supported by the National Health and Medical Research Council of Australia (Program grant to JGB [1092789]; Research Fellowship to JGB [1077636]); Australian Research Council Future Fellowship to FJIF 
[FT130101122]; Australian Government Research Training Program Scholarship to LK; Monash Postgraduate Publication Award to LK. PATH's Malaria Vaccine Initiative provided funding for the clinical trial. JGB, FJIF, LK, GF, and DRD are members of the Australian Centre for Research Excellence in Malaria Elimination, funded by the NHMRC [1134989]. ISGlobal is a member of the CERCA Program, Generalitat de Catalunya. The Manhiça Health Research Centre receives core funding from the Spanish Agency for International Cooperation and Development (AECID). The Burnet Institute is supported by a Victorian State Government Operational Infrastructure Support grant, and the NHMRC Independent Research Institutes Infrastructure Support Scheme.

\section{Availability of data and materials}

The data sets used and/or analyzed during the current study are available from the corresponding author on reasonable request.

\section{Authors' contributions}

LK performed the experiments and descriptive data analysis. PAA developed and performed the statistical modeling. DRD generated the recombinant protein. IU was involved in the sample selection. JS and JJA were involved in the clinical trial. $L K, G F, F J I F, C D$, and JGB were involved in the study design. LK and JGB wrote the manuscript, which was reviewed by all authors. All authors read and approved the final manuscript.

\section{Ethics approval and consent to participate}

Parents/guardians of participants provided written informed consent, and ethics approval was obtained by the following: Mozambican National Health and Bioethics Committee; Hospital Clınic of Barcelona Ethics Committee; PATH Research Ethics Committee; Alfred Human Research and Ethics Committee (ethics approval number 174/18).

\section{Consent for publication}

Not applicable.

\section{Competing interests}

The authors declare that they have no competing interests.

\section{Publisher's Note}

Springer Nature remains neutral with regard to jurisdictional claims in published maps and institutional affiliations.

\begin{abstract}
Author details
${ }^{1}$ Burnet Institute, Melbourne, Australia. ${ }^{2}$ Department of Immunology and Pathology, Monash University, Melbourne, Australia. ${ }^{3}$ Department of Epidemiology and Preventative Medicine, Monash University, Melbourne, Australia. ${ }^{4}$ ISGlobal, Hospital Clínic Universitat de Barcelona, Barcelona, Catalonia, Spain. ${ }^{5}$ Centro de Investigação em Saúde de Manhiça, Maputo, Mozambique. ${ }^{6}$ Faculdade de Medicina, Universidade Eduardo Mondlane (UEM), Maputo, Mozambique. ${ }^{7}$ Centre for Epidemiology and Biostatistics, Melbourne School of Population and Global Health, The University of Melbourne, Melbourne, Australia. ${ }^{8}$ Department of Microbiology, Monash University, Clayton, Australia. ${ }^{9}$ Department of Medicine, The University of Melbourne, Parkville, Australia.
\end{abstract}

Received: 16 November 2018 Accepted: 31 January 2019

Published online: 25 February 2019

\section{References}

1. RTSS Clinical Trial Partnerships. Efficacy and safety of RTS,S/AS01 malaria vaccine with or without a booster dose in infants and children in Africa: final results of a phase 3, individually randomised, controlled trial. Lancet. 2015;386(9988):31-45.

2. European Medicines Agency: Mosquirix to be used for vaccination of young children, together with established antimalarial interventions. 2015.

3. World Health Organization: Malaria vaccine: WHO position paper - January 20162016.

4. World Health Organization: Ghana, Kenya and Malawi to take part in WHO malaria vaccine pilot programme. 2017

5. Malaria Vaccine Funders Group. Malaria vaccine technology roadmap. 2013.

6. Casares S, Brumeanu T-D, Richie TL. The RTS,S malaria vaccine. Vaccine. 2010;28(31):4880-94.
7. White MT, Verity R, Griffin JT, Asante KP, Owusu-Agyei S, Greenwood B, Drakeley C, Gesase S, Lusingu J, Ansong D. Immunogenicity of the RTS,S/ AS01 malaria vaccine and implications for duration of vaccine efficacy: secondary analysis of data from a phase 3 randomised controlled trial. Lancet Infect Dis. 2015;15(12):1450-8.

8. Ubillos I, Ayestaran A, Nhabomba AJ, Dosoo D, Vidal M, Jiménez A, Jairoce C, Sanz H, Aguilar R, Williams NA. Baseline exposure, antibody subclass, and hepatitis $B$ response differentially affect malaria protective immunity following RTS,S/AS01E vaccination in African children. BMC Med. 2018;16(1):197.

9. Foquet L, Hermsen CC, van Gemert G-J, Van Braeckel E, Weening KE, Sauerwein R, Meuleman P, Leroux-Roels G. Vaccine-induced monoclonal antibodies targeting circumsporozoite protein prevent Plasmodium falciparum infection. J Clin Invest. 2014;124(1):140.

10. Chaudhury S, Ockenhouse CF, Regules JA, Dutta S, Wallqvist A, Jongert E, Waters NC, Lemiale F, Bergmann-Leitner E. The biological function of antibodies induced by the RTS,S/AS01 malaria vaccine candidate is determined by their fine specificity. Malaria J. 2016;15(1):301.

11. Schwenk R, Asher LV, Chalom I, Lanar D, Sun P, White K, Keil D, Kester KE, Stoute J, Heppner DG. Opsonization by antigen-specific antibodies as a mechanism of protective immunity induced by Plasmodium falciparum circumsporozoite protein-based vaccine. Parasite Immunol. 2003;25(1):17-25.

12. Feng JQ, Mozdzanowska K, Gerhard W. Complement component C1q enhances the biological activity of influenza virus hemagglutinin-specific antibodies depending on their fine antigen specificity and heavy-chain isotype. J Virol. 2002;76(3):1369-78.

13. Mehlhop E, Nelson S, Jost CA, Gorlatov S, Johnson S, Fremont DH, Diamond MS, Pierson TC. Complement protein C1q reduces the stoichiometric threshold for antibody-mediated neutralization of West Nile virus. Cell Host Microbe. 2009;6(4):381-91.

14. MacLennan CA, Gondwe EN, Msefula CL, Kingsley RA, Thomson NR, White SA, Goodall M, Pickard DJ, Graham SM, Dougan G. The neglected role of antibody in protection against bacteremia caused by nontyphoidal strains of Salmonella in African children. J Clin Invest. 2008;118(4):1553-62.

15. Boyle MJ, Reiling L, Feng G, Langer C, Osier FH, Aspeling-Jones $H$, Cheng YS, Stubbs J, Tetteh KK, Conway DJ, et al. Human antibodies fix complement to inhibit Plasmodium falciparum invasion of erythrocytes and are associated with protection against malaria. Immunity. 2015; 42(3):580-90.

16. Behet MC, Kurtovic L, van Gemert G-J, Haukes CM, Siebelink-Stoter R, Graumans W, van de Vegte-Bolmer MG, Scholzen A, Langereis JD, Diavatopoulos DA. The complement system contributes to functional antibody-mediated responses induced by immunization with Plasmodium falciparum malaria sporozoites. Infect Immun. 2018;|AI:00920-17.

17. Kurtovic L, Behet MC, Feng G, Reiling L, Chelimo K, Dent AE, Mueller I, Kazura JW, Sauerwein RW, Fowkes FJl, et al. Human antibodies activate complement against Plasmodium falciparum sporozoites, and are associated with protection against malaria in children. BMC Med. 2018;16(1):61.

18. Alonso PL, Sacarlal J, Aponte JJ, Leach A, Macete E, Milman J, Mandomando I, Spiessens B, Guinovart C, Espasa M. Efficacy of the RTS,S/AS02A vaccine against Plasmodium falciparum infection and disease in young African children: randomised controlled trial. Lancet. 2004:364(9443):1411-20.

19. Stanisic DI, Richards JS, McCallum FJ, Michon P, King CL, Schoepflin S, Gilson PR, Murphy VJ, Anders RF, Mueller I. Immunoglobulin G subclass-specific responses against Plasmodium falciparum merozoite antigens are associated with control of parasitemia and protection from symptomatic illness. Infect Immun. 2009;77(3):1165-74.

20. Drew DR, Hodder AN, Wilson DW, Foley M, Mueller I, Siba PM, Dent AE, Cowman AF, Beeson JG. Defining the antigenic diversity of Plasmodium falciparum apical membrane antigen 1 and the requirements for a multi-allele vaccine against malaria. PLoS One. 2012;7(12):e51023.

21. Weaver R, Reiling L, Feng G, Drew DR, Mueller I, Siba PM, Tsuboi T, Richards JS, Fowkes FJ, Beeson JG. The association between naturally acquired IgG subclass specific antibodies to the PfRH5 invasion complex and protection from Plasmodium falciparum malaria. Sci Rep. 2016;6:33094.

22. Ondigo BN, Park GS, Gose SO, Ho BM, Ochola LA, Ayodo GO, Ofulla AV, John CC. Standardization and validation of a cytometric bead assay to assess antibodies to multiple Plasmodium falciparum recombinant antigens. Malar J. 2012;11(1):427 
23. Cohen J. Statistical power analysis for the behavioral sciences. 2nd ed. Hillsdale: Erlbaum Associates; 1988.

24. Elliott SR, Fowkes FJ, Richards JS, Reiling L, Drew DR, Beeson JG. Research priorities for the development and implementation of serological tools for malaria surveillance. F1000prime reports. 2014;6:6-100.

25. Irani V, Guy AJ, Andrew D, Beeson JG, Ramsland PA, Richards JS. Molecular properties of human IgG subclasses and their implications for designing therapeutic monoclonal antibodies against infectious diseases. Mol Immunol. 2015;67(2):171-82.

26. Alving CR, Peachman KK, Rao M, Reed SG. Adjuvants for human vaccines. Curr Opin Immunol. 2012;24(3):310-5.

27. Stoute JA, Slaoui M, Heppner DG, Momin P, Kester KE, Desmons P, Wellde BT, Garçon N, Krzych U, Marchand M. A preliminary evaluation of a recombinant circumsporozoite protein vaccine against Plasmodium falciparum malaria. N Engl J Med. 1997;336(2):86-91.

28. Kester KE, McKinney DA, Tornieporth N, Ockenhouse CF, Heppner DG, Hall T, Krzych U, Delchambre M, Voss G, Dowler MG. Efficacy of recombinant circumsporozoite protein vaccine regimens against experimental Plasmodium falciparum malaria. J Infect Dis. 2001;183(4):640-7.

29. Kester KE, McKinney DA, Tornieporth N, Ockenhouse CF, Heppner DG, Hall T, Wellde BT, White K, Sun P, Schwenk R. A phase I/lla safety, immunogenicity, and efficacy bridging randomized study of a two-dose regimen of liquid and lyophilized formulations of the candidate malaria vaccine RTS,S/AS02A in malaria-naive adults. Vaccine. 2007;25(29):5359-66.

30. Krishnamurty AT, Thouvenel CD, Portugal S, Keitany GJ, Kim KS, Holder A, Crompton PD, Rawlings DJ, Pepper M. Somatically hypermutated Plasmodium-specific lgM+ memory B cells are rapid, plastic, early responders upon malaria rechallenge. Immunity. 2016;45(2):402-14.

31. Stanisic DI, Fowkes FJI, Koinari M, Javati S, Lin E, Kiniboro B, Richards JS, Robinson LJ, Schofield L, Kazura JW, et al. Acquisition of antibodies against Plasmodium falciparum merozoites and malaria immunity in young children and the influence of age, force of infection, and magnitude of response. Infect Immun. 2015;83(2):646-60.

32. Diebolder CA, Beurskens FJ, de Jong RN, Koning RI, Strumane K, Lindorfer MA, Voorhorst M, Ugurlar D, Rosati S, Heck AJ. Complement is activated by IgG hexamers assembled at the cell surface. Science. 2014;343(6176):1260-3.

33. Cragg MS, Morgan SM, Chan HC, Morgan BP, Filatov A, Johnson PW, French RR, Glennie MJ. Complement-mediated lysis by anti-CD20 mAb correlates with segregation into lipid rafts. Blood. 2003;101(3):1045-52.

34. Teeling JL, Mackus WJ, Wiegman LJ, van den Brakel JH, Beers SA, French RR, van Meerten T, Ebeling S, Vink T, Slootstra JW. The biological activity of human CD20 monoclonal antibodies is linked to unique epitopes on CD20. J Immunol. 2006;177(1):362-71.

35. Regules JA, Cicatelli SB, Bennett JW, Paolino KM, Twomey PS, Moon JE, Kathcart AK, Hauns KD, Komisar JL, Qabar AN. Fractional third and fourth dose of RTS,S/AS01 malaria candidate vaccine: a phase 2a controlled human malaria parasite infection and immunogenicity study. J Infect Dis. 2016; 214(5):762-71.

36. Kester KE, Cummings JF, Ockenhouse CF, Nielsen R, Hall BT, Gordon DM, Schwenk RJ, Krzych U, Holland CA, Richmond G. Phase 2a trial of 0, 1, and 3 month and 0,7 , and 28 day immunization schedules of malaria vaccine RTS,S/AS02 in malaria-naive adults at the Walter Reed Army Institute of Research. Vaccine. 2008:26(18):2191-202.

37. Kester KE, Cummings JF, Ofori-Anyinam O, Ockenhouse CF, Krzych U, Moris P, Schwenk R, Nielsen RA, Debebe Z, Pinelis E. Randomized, double-blind, phase 2a trial of falciparum malaria vaccines RTS,S/AS01B and RTS,S/AS02A in malaria-naive adults: safety, efficacy, and immunologic associates of protection. J Infect Dis. 2009;200(3):337-46.

38. Bejon P, Lusingu J, Olotu A, Leach A, Lievens M, Vekemans J, Mshamu S, Lang T, Gould J, Dubois M-C. Efficacy of RTS,S/AS01E vaccine against malaria in children 5 to 17 months of age. N Engl J Med. 2008;359(24):2521-32.

39. Clinical trials Partnership RTSS. Efficacy and safety of the RTS,S/AS01 malaria vaccine during 18 months after vaccination: a phase 3 randomized, controlled trial in children and young infants at 11 African sites. PLoS Med. 2014;11: e1001685.

40. Zavala F, Cochrane AH, Nardin EH, Nussenzweig RS, Nussenzweig V. Circumsporozoite proteins of malaria parasites contain a single immunodominant region with two or more identical epitopes. J Exp Med. 1983;157(6):1947-57

41. Brown AE, Webster HK, Pavanand K, Permpanich B, Sookto P, Sattabongkot J, Gingrich JB. Comparison of antibody responses to the circumsporozoite protein repeat region and to intact sporozoites during acute falciparum malaria. Trans R Soc Trop Med Hyg. 1989;83(2):154-7.

42. Hollingdale MR, Nardin EH, Tharavanij S, Schwartz A, Nussenzweig R. Inhibition of entry of Plasmodium falciparum and $P$. vivax sporozoites into cultured cells; an in vitro assay of protective antibodies. J Immunol. 1984; 132(2):909-13.

43. Bongfen SE, Ntsama PM, Offner S, Smith T, Felger I, Tanner M, Alonso P, Nebie I, Romero JF, Silvie O. The N-terminal domain of Plasmodium falciparum circumsporozoite protein represents a target of protective immunity. Vaccine. 2009;27(2):328-35.

44. Chatterjee $S$, Wery $M$, Sharma $P$, Chauhan V. A conserved peptide sequence of the Plasmodium falciparum circumsporozoite protein and antipeptide antibodies inhibit Plasmodium berghei sporozoite invasion of Hep-G2 cells and protect immunized mice against $P$. berghei sporozoite challenge. Infect Immun. 1995:63(11):4375-81.

45. Rathore D, Nagarkatti R, Jani D, Chattopadhyay R, de la Vega P, Kumar S, McCutchan TF. An immunologically cryptic epitope of Plasmodium falciparum circumsporozoite protein facilitates liver cell recognition and induces protective antibodies that block liver cell invasion. J Biol Chem. 2005;280(21):20524-9.

46. Plassmeyer ML, Reiter K, Shimp RL, Kotova S, Smith PD, Hurt DE, House B, Zou X, Zhang Y, Hickman M. Structure of the Plasmodium falciparum circumsporozoite protein, a leading malaria vaccine candidate. J Biol Chem. 2009;284(39):26951-63.

47. Calle J, Nardin EH, Clavijo P, Boudin C, Stüber D, Takacs B, Nussenzweig R, Cochrane A. Recognition of different domains of the Plasmodium falciparum CS protein by the sera of naturally infected individuals compared with those of sporozoite-immunized volunteers. J Immunol. 1992;149(8):2695-701.

48. White MT, Bejon P, Olotu A, Griffin JT, Bojang K, Lusingu J, Salim N, Abdulla S, Otsyula N, Agnandji ST. A combined analysis of immunogenicity, antibody kinetics and vaccine efficacy from phase 2 trials of the RTS,S malaria vaccine. BMC Med. 2014;12(1):117.

49. Aide P, Dobaño C, Sacarlal J, Aponte JJ, Mandomando I, Guinovart C, Bassat Q, Renom M, Puyol L, Macete E. Four year immunogenicity of the RTS,S/ AS02A malaria vaccine in Mozambican children during a phase Ilb trial. Vaccine. 2011;29(35):6059-67.

50. Campo JJ, Dobaño C, Sacarlal J, Guinovart C, Mayor A, Angov E, Dutta S, Chitnis C, Macete E, Aponte JJ. Impact of the RTS,S malaria vaccine candidate on naturally acquired antibody responses to multiple asexual blood stage antigens. PLoS One. 2011;6(10):e25779.

51. Illingworth J, Butler NS, Roetynck S, Mwacharo J, Pierce SK, Bejon P, Crompton PD, Marsh K, Ndungu FM. Chronic exposure to Plasmodium falciparum is associated with phenotypic evidence of B and T cell exhaustion. J Immunol. 2012;1202438:1038-47.
Ready to submit your research? Choose BMC and benefit from:
- fast, convenient online submission
- thorough peer review by experienced researchers in your field
- rapid publication on acceptance
- support for research data, including large and complex data types
- gold Open Access which fosters wider collaboration and increased citations
- maximum visibility for your research: over $100 \mathrm{M}$ website views per year
At BMC, research is always in progress.
Learn more biomedcentral.com/submissions 